\title{
Diffusion of Iron and Cobalt in an Intermetallic Compound of Ti-54 at\% Al
}

\author{
Yoshiaki Iijima \\ Department of Materials Science, Graduate School of Engineering, \\ Tohoku University, Sendai 980-8579, Japan \\ Chan-Gyu Lee \\ Department of Materlals Sclence and Engineering, Changwon \\ National University, Changwon 641-773, Republic of Korea \\ Seung-Eon Kim, Yong-Tae Lee and Hak-Min Kim \\ Korea Institute of Machinery and Metals, \\ Changwon 641-010, Republic of Korea
}

(R'eceived January 28, 1998)

\section{ABSTRACT}

Diffusion coefficients of ${ }^{59} \mathrm{Fe}$ and ${ }^{57} \mathrm{Co}$ in an intermetallic compound $\mathrm{Ti}-54$ at\% Al have been determined in the temperature range between 1000 and $1538 \mathrm{~K}$ by use of the serial radio-frequency sputter-microsectioning technique. In the whole temperature range of the present experiments, the relation $D_{T_{i}}>D_{C_{0}}>D_{F_{*}}$, has been recognized. The Arrhenius plots of the diffusion coefficients of ${ }^{59} \mathrm{Fe}$ and ${ }^{57} \mathrm{Co}$ show linear relationships which are represented by the equations:

$$
\begin{aligned}
& D_{F_{\bullet}}=1.30 \times 10^{-2} \exp \left(-363 \mathrm{kJmol}^{-1} / \mathrm{RT}\right) \mathrm{m}^{2} \mathrm{~s}^{-4} \\
& \text { and } \\
& \mathrm{D}_{\mathrm{C}_{0}}=1.12 \times 10^{-3} \exp \left(-318 \mathrm{kJmol}^{-1} / \mathrm{RT}\right) \mathrm{m}^{2} \mathrm{~s}^{-1}
\end{aligned}
$$

\section{INTRODUCTION}

Intermetallic compounds and ordered alloys have recently attracted much attention for applications as structural materials at high temperatures /1-3/. Especially, titanium-aluminides, including the $\gamma$-phase TiAl, are highly promising structural materials, because these alloys exhibit high heat-resisting and lightweight as well as superior mechanical properties $13 /$. At ambient
\end{abstract}

temperature, however, low ductility and low deformability of the $\gamma$-phase TiAl alloys have been observed. To overcome these problems many attempts have been made to survey chemical compositions and heat treatments of the alloys $/ 3 /$. The use of high purity metals of Ti and Al and careful preparation of the single $\gamma$-phase TiAl ingots are found to be highly effective in improving the ductility of the compounds /4/. Furthermore, it has been found that addition of several elements such as V, Cr, Mn and Mo improves the ductility and oxidation-resistance of the $\gamma$-phase TiAl compound $/ 3 /$. Based on the phase equilibria in $\mathrm{Ti}-\mathrm{Al}$ alloys, $\mathrm{Ti}-\mathrm{rich}$ $\gamma$-TiAl alloys including the $\mathrm{Ti}_{3} \mathrm{Al}$ phase have been developed for the practical applications.

Diffusion study is indispensable to understand the behavior of the alloying elements and to improve the alloys to higher quality. However, diffusion experiments in intermetallic compounds are generally laborious in comparison with those in pure metals and metallic solid solutions, because it is not easy to obtain high purity sound specimens of a single phase without defects such as voids and inclusions. For the intermetallic compounds with anisotropic structures it is preferable to use single crystal specimens. Consequently, diffusion studies on the B2 type alloys are relatively numerous, while comparatively scarce information is available on 
diffusion data in intermetallic compounds of $\mathrm{Ll}_{2}$ type ( $\mathrm{Cu}_{3} \mathrm{Au}$ type), $\mathrm{DO}_{3}$ type ( $\mathrm{Fe}_{3} \mathrm{Si}$ type), A15 type $\mathrm{Nb}_{3} \mathrm{Sn}$ type), and $\mathrm{B8}_{2}$ type (NiAs type) structures $/ 5-7 /$. Only a few data can be found on diffusion in $\mathrm{Ll}_{0}$ type ( $\mathrm{CuAu}$ type) compounds. The $\gamma$-phase $\mathrm{TiAl}$ has $\mathrm{Ll} \mathrm{l}_{0}$ structure, which is slightly tetragonally distorted face-centered cubic (fcc) lattice with $\mathrm{CuAu}$ type order. The ratio between lattice parameters in the direction of the tetragonal axis and perpendicular to the axis is 1.02 close to unity. So far, interdiffusion study in the $\gamma$-phase Ti-Al with couples of pure $\mathrm{Ti}$ and $\mathrm{Ti}-54$ at\% $\mathrm{Al}$ alloy has been performed by Ouchi et al. 18/. Recently, Sprengel et al. /9/ have studied interdiffusion in $\gamma$-phase-TiAl using single phase couples of the $\gamma$-phase TiAl. Tracer selfdiffusion of ${ }^{44} \mathrm{Ti}$ in the $\gamma$-phase TiAl. (Ti-54 at\%Al alloy) has been studied by Kroll et al. /10/. However, diffusion study of various solute elements in the intermetallic compound TiAl has not so far been carried out.

For diffusion experiments on the titanium-aluminides some special attention must be paid. In particular, titanium and aluminium are very active with oxygen. Then, the surface of the titanium-aluminides is very easily covered by oxide layers with increase of temperature. Nevertheless, the oxidation of the surface of the specimen during diffusion annealing must be avoided to obtain reliable penetration profiles of tracers. According to Kroll et al. /10/, the diffusivity of $\mathrm{Ti}$ in the $\gamma$-phase TiAl is relatively low in comparison with the self-diffusivities in fcc pure metals. Then, to obtain the diffusion coefficients of substitutional solutes in the $\gamma$-phase TiAl over a wide temperature range the measurements of submicron penetration profiles are required. It can be performed only by use of the microsectioning technique. In the present work, to elucidate the diffusion behavior of iron and cobalt solutes in the single $\gamma$-phase TiAl (Ti-54at\% Al alloy), diffusion experiments have been carried out by a serial radiofrequency sputter-microsectioning technique with the radioactive tracers ${ }^{59} \mathrm{Fe}$ and ${ }^{57} \mathrm{Co}$ in the temperature range from 1000 to $1538 \mathrm{~K}$.

\section{EXPERIMENTAL PROCEDURE}

Buttons of Ti-54at\% Al alloy were made by low pressure argon arc-melting pure Ti blocks with pure Al blocks of $99.99 \%$ purity. Chemical analysis of the pure
Ti showed the impurities to be O: $0.050, \mathrm{Mg}: 0.014, \mathrm{Si}$ : 0.010, Fe: 0.009, N: 0.005, C: 0.004, H: 0.025 and Mr: 0.002 mass $\%$. To homogenize the buttons, the arcmelting was repeated a few times. Then, small blocks were machined from the buttons and melted again in a high frequency ffoating zone furnace in high argon pressure. Finally, a rod of the alloy $12 \mathrm{~mm}$ in diameter was made. By this zone-melting a grain size of about 2 to $3 \mathrm{~mm}$ was obtained, which was much larger than that in the buttons. Furthermore, the grain boundaries were smooth in comparison with those in the buttons. Thus, the zone-melting would be effective in purifying the alloy $/ 4 /$. The rod was cut to make disc specimens $2 \mathrm{~mm}$ in thickness. The ffat face of the specimens was ground through metallographic papers and carefully polished. To remove any surface damage the surface layer of 1 $2 \mu \mathrm{m}$ was sputter-etched.

The radioisotope ${ }^{59} \mathrm{Fe}$ ( $\gamma$-rays, 1.095 and $1.292 \mathrm{MeV}$; half-life, $45.6 \mathrm{~d})$ was supplied in a form of ferric chloride in $0.5 \mathrm{kmol} \mathrm{m}^{-3} \mathrm{HCl}$ solution from Dupont NEN Research Products, U.S.A. The radioisotope ${ }^{57} \mathrm{Co}$ ( $\gamma$-ray, $0.122 \mathrm{MeV}$; half-life, $270 \mathrm{~d}$ ) was supplied in a form of cobaltous chloride in $0.1 \mathrm{kmol} \mathrm{m}^{-3} \mathrm{HCl}$ solution from ICN Radiochemicals, Inc., U.S.A. The radionuclidic purity of the isotopes was more than $99 \%$. The concentration of the radioactivities of ${ }^{59} \mathrm{Fe}$ and ${ }^{57} \mathrm{Co}$ was $37 \mathrm{MBq}$ in $10^{-7}$ and $7 \times 10^{-9} \mathrm{~m}^{3}$, respectively, of the total volume of the solutions. $A$ drop of the solution containing ${ }^{59} \mathrm{Fe}$ or ${ }^{57} \mathrm{Co}$ was put into $0.1 \times 10^{-6} \mathrm{~m}^{3}$ of dimethyl-sulfoxide. Then ${ }^{59} \mathrm{Fe}$ or ${ }^{57} \mathrm{Co}$ isotope was electroplated from the dimethyl-sulfoxide on the mirrorlike surface of the specimen. To avoid oxidation of the surface of the specimen during the diffusion annealing, sponge titanium previously degassed at $1273 \mathrm{~K}$ for $2 \mathrm{ks}$ was used as an absorber for residual oxygen gas in an evacuated diffusion capsule. Each specimen was put in one terminal of a long quartz tube about $50 \mathrm{~cm}$ in length and the titanium sponge was put in its other terminal. The quartz tube was sealed at a pressure less than $3 \times$ $10^{-4} \mathrm{~Pa}$, and then the titanium sponge side of the tube was put into an electric furnace controlled at $1050 \mathrm{~K}$ for $60 \mathrm{ks}$ to absorb the residual gas in the tube. After this treatment, the specimen side of the tube was put into the electric furnace controlled within $\pm 1 \mathrm{~K}$, and the diffusion annealing was made at temperatures in the range from 1000 to $1538 \mathrm{~K}$ for 2.4 to $151 \mathrm{ks}$. 
The serial radio-frequency sputter-microsectioning method was employed to measure the penetration profiles of the radioisotope into the specimen. By applying radio-frequency power with a peak to peak voltage of $1.6 \mathrm{kV}$ at $13.56 \mathrm{KHz}$ the specimen was sputtered in an argon ffow discharge. The sputtered-off material was collected on an aluminium foil. The serial sectioning of the whole profile was achieved by moving the collector foil step by step like a roll film in a camera without interrupting the radio-frequency supply. For each specimen 15 30 consecutive sections were sputtered. The section thicknesses were determined from the sputtering rate and the individual sputtering time. A constant fraction more than $60 \%$ of the sputtered-off material could be collected on the aluminium foil. The intensity of $\gamma$-ray from each section was measured by a well-type T1-activated Nal scintillation detector in conjunction with a 1024 channels pulse height analyzer.

\section{RESULTS AND DISCUSSION}

For one-dimensional volume diffusion of a tracer from an infinitesimally thin surface layer into a sufficiently long rod, the solution of Fick's second law is given by

$$
\begin{aligned}
& I(X, t) \propto C(X, t)= \\
& \quad\{M / \sqrt{\pi D t}\} \exp \left(-X^{2} / 4 D t\right),
\end{aligned}
$$

where $I(X, t)$ and $C(X, t)$ are the intensity of the radioactivity and the concentration, respectively, of the tracer at a distance $X$ from the original surface after a diffusion time $t . D$ is the volume diffusion coefficient of the tracer and $M$ is the total amount of tracer deposited on the surface before the diffusion.

Figures 1 and 2 show the plots of $I n I(X, t)$ vs $X^{2}$ for the diffusion of ${ }^{59} \mathrm{Fe}$ in the $\gamma$-phase TiAl (Ti-54at\% Al alloy). Figures 3 and 4 show similar penetration profiles of ${ }^{57} \mathrm{Co}$ in the alloy. In proof of eq. (1), all the plots in Figs. 1 to 4 show linearity, and thus it can be said that the volume diffusion has been concerned. The diffusion coefficients of iron and cobalt calculated from the slope of the plots are listed in Table 1. Their Arrhenius plots are shown in Fig. 5 in comparison with the

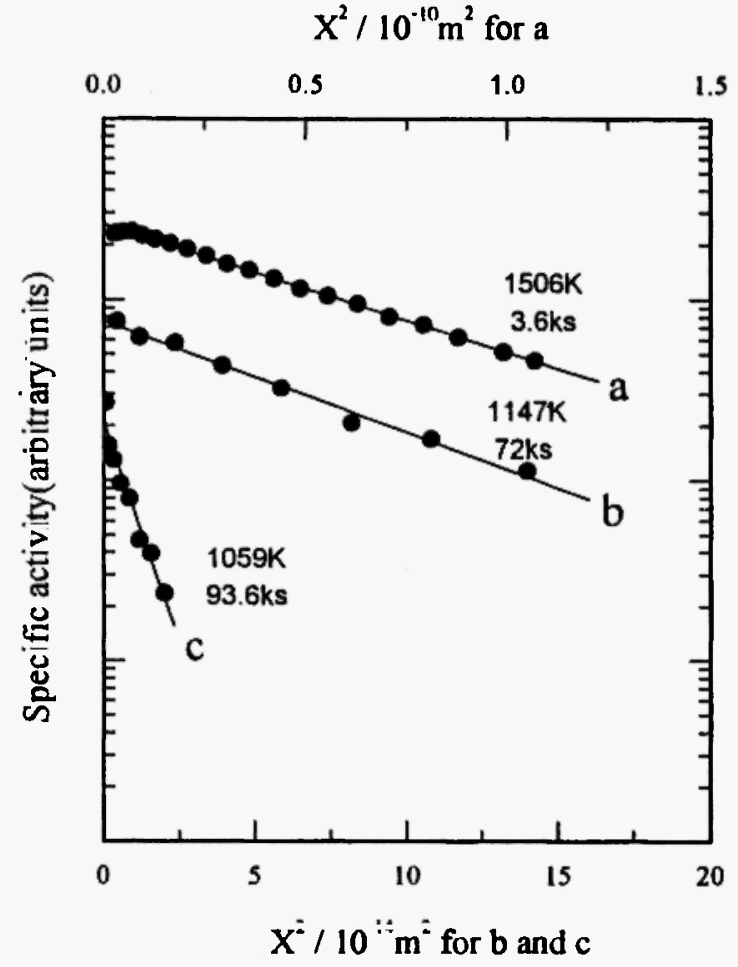

Fig. 1: Penetration profiles for diffusion of ${ }^{59} \mathrm{Fe}$ in Ti-54 at\%Al alloy at 1059, 1147 and $1506 \mathrm{~K}$.

$$
\mathrm{X}^{2} / 10^{-12} \mathrm{~m}^{2} \text { for } \mathrm{c}, \mathrm{d} \text { and } \mathrm{e}
$$

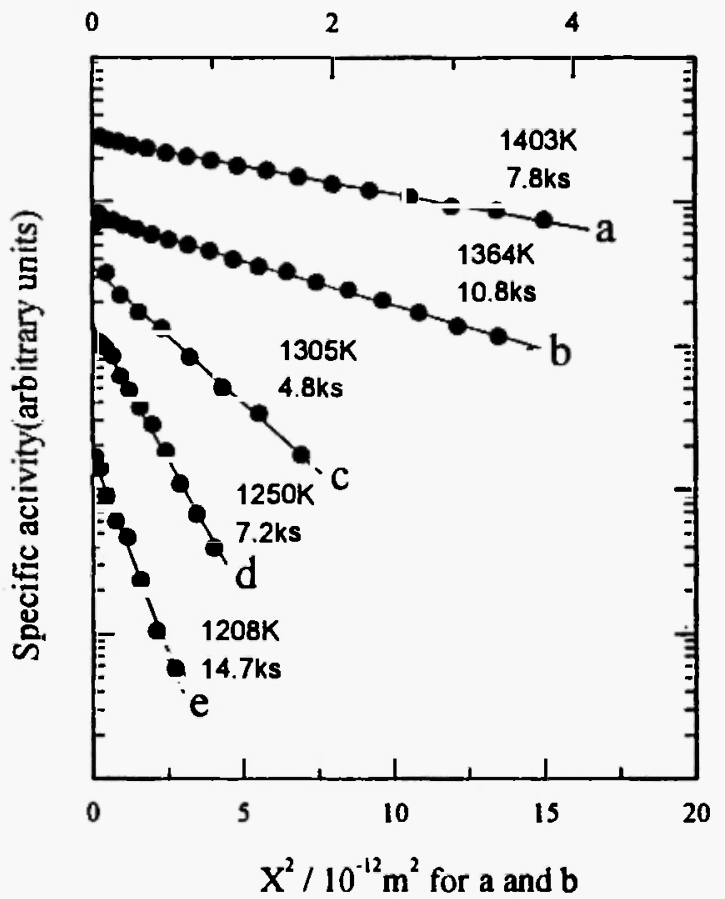

Fig. 2: Penetration profiles for diffiusion of ${ }^{39} \mathrm{Fe}$ in Ti-54at\%Al alloy at 1208, 1250,1305, 1364 and $1403 \mathrm{~K}$. 


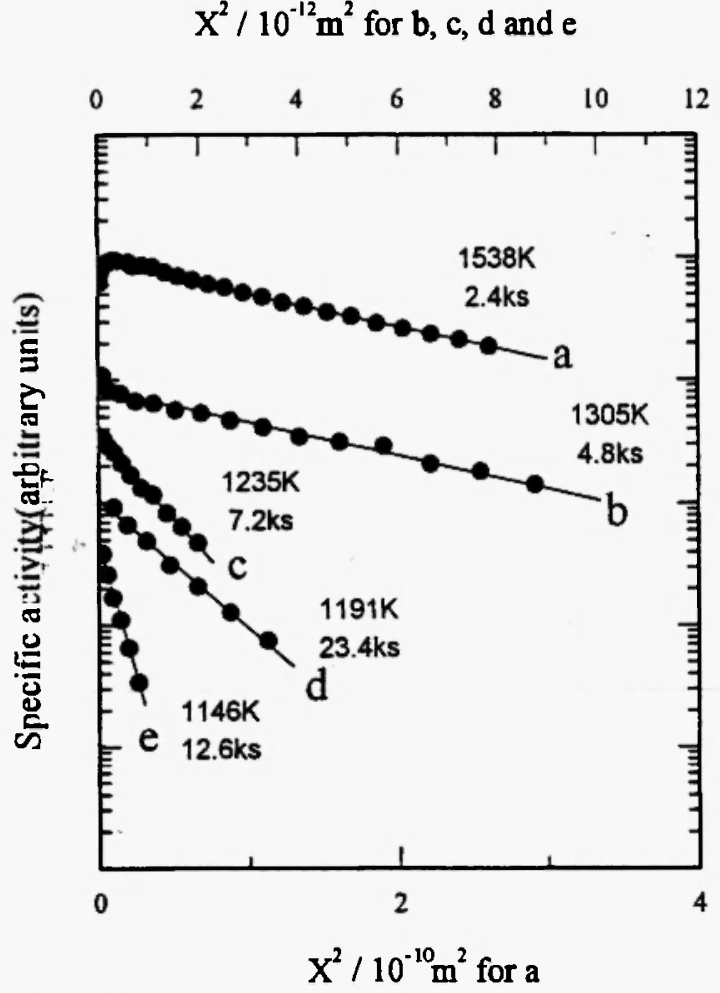

Fig. 3: Penetration profiles for diffusion of ${ }^{57} \mathrm{Co}$ in Ti-54at\%Al alloy at 1146, 1191, 1235, 1305 and $1538 \mathrm{~K}$.

self-diffusion coefficients of titanium in the alloy by Kroll et al. 110\%. At higher temperatures, the magnitude of the diffusion coefficients of cobalt is nearly equal to that of the self-diffusion coefficient of titanium; however, in the lower temperatures, the former is slightly smaller than the latter, and the differencc between them increases with decrease of temperature. On the other hand, the diffusion coefficient of iron is smaller than those of cobalt and titanium in the whole temperature range. The diffusion coefficients of iron and cobalt in the $\gamma$-phase TiAl (Ti-54at\% Al alloy) show linear Arrhenius relationships, as shown in Fig. 5. Then, the pre-exponential factor, $D_{0}$ and the activation energy, $Q$, are obtained to be $1.30 \times 10^{-2} \mathrm{~m}^{2} \mathrm{~s}^{-1}$ and 363 $\mathrm{kJmol}^{-1}$ for iron and $1.12 \times 10^{-3} \mathrm{~m}^{2} \mathrm{~s}^{-1}$ and $318 \mathrm{kJmol}^{-1}$ for cobalt, respectively. On the other hand, the values of $D_{0}$ and $Q$ for the self-diffiusion of titanium in the alloy have been obtained to be $1.53 \times 10^{-4} \mathrm{~m}^{2} \mathrm{~s}^{-1}$ and 291 $\mathrm{kJmol}^{-1}$, respectively /10/. Therefore, both the values of

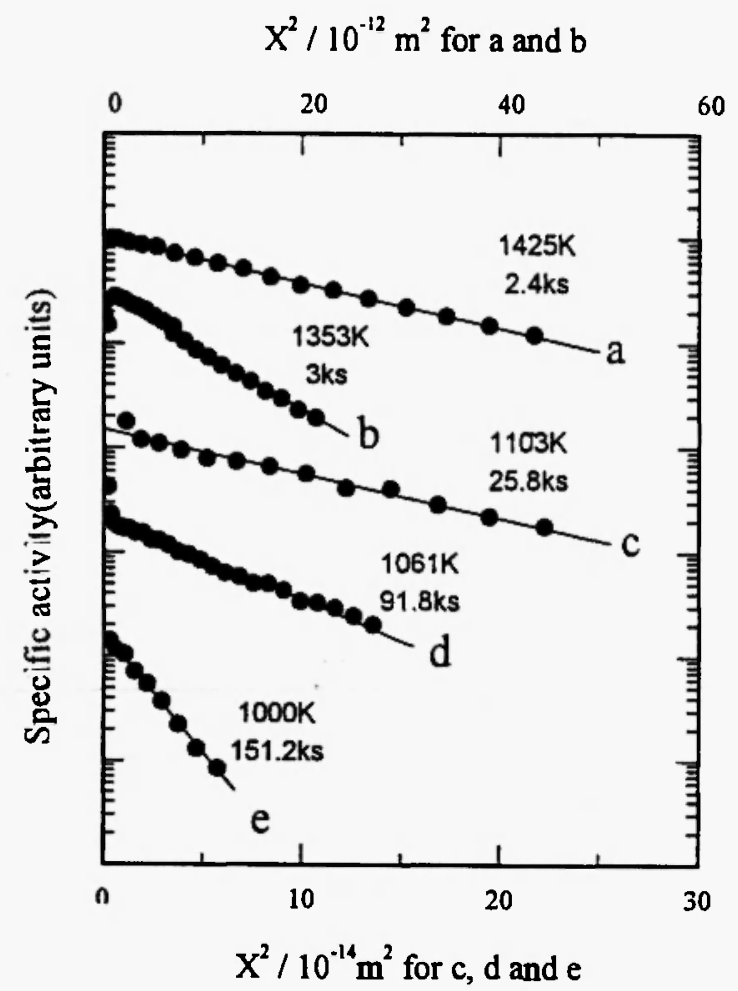

Fig. 4: Penetration profiles for diffusion of ${ }^{57} \mathrm{Co}$ in Ti-54at\%Al alloy at 1000,1061, 1103, 1353 and $1425 \mathrm{~K}$.

$D_{0}$ and $Q$ for iron and cobalt are larger than those for the self-diffusion of titanium in the alloy.

According to the well-known empirical rules for self-diffusion in fcc pure metals $/ 11 /$, (1) the value of $D_{0}$ lies in the range between $5 \times 10^{-6}$ and $10^{-3} \mathrm{~m}^{2} \mathrm{~s}^{-1}$; (2) the diffusion coefficient at the melting temperature, $T_{m}$, has a value of about $5.5 \times 10^{-13} \mathrm{~m}^{2} \mathrm{~s}^{-1}$; (3) the ratio $Q / \mathrm{RT}_{\mathrm{m}}$ is approximately 18.4. The values of $D$ at $T_{m}$ for iron and cobalt are estimated to be $7.2 \times 10^{-14}$ and $2.1 \times 10^{-13}$ $\mathrm{m}^{2} \mathrm{~s}^{-1}$, respectively, if the peritectic temperature of the $\gamma$-phase TiAl ( $=1708 \mathrm{~K}$ ) was used instead of $T_{m}$. Therefore, the rules (1) and (2) are fairly consistent with the values of the $\gamma$-phase TiAl compound. However, the ratios of $\mathrm{Q} / \mathrm{RT}_{\mathrm{m}}$ for iron, cobalt and titanium are obtained to be 25.6, 22.4 and 20.5, respectively. All these values are larger than 18.4 for fcc pure metals. This means probably that the atomic cohesion in the intermetallic compound with $\mathrm{L}_{0}$ structure is stronger than that in fce pure metals. 
Table 1

Diffusion coefficients of ${ }^{59} \mathrm{Fe}$ and ${ }^{57} \mathrm{Co}$ in $\gamma$-phase TiAl alloy

\begin{tabular}{|c|c|c|c|}
\hline $\begin{array}{l}\text { Diffusing } \\
\text { atom }\end{array}$ & $\begin{array}{c}\text { Temperature } \\
\text { (K) }\end{array}$ & $\begin{array}{l}\text { Diffusion } \\
\text { time } \\
\text { (s) }\end{array}$ & $\begin{array}{l}\text { Diffusion coefficient } \\
\qquad\left(\mathrm{m}^{2} \cdot \mathrm{s}^{-1}\right)\end{array}$ \\
\hline \multirow{8}{*}{$\mathrm{Fe}$} & 1506 & $3.60 \times 10^{3}$ & $4.19 \times 10^{-15}$ \\
\hline & 1403 & $7.80 \times 10^{3}$ & $4.06 \times 10^{-16}$ \\
\hline & 1364 & $1.08 \times 10^{4}$ & $1.61 \times 10^{-16}$ \\
\hline & 1305 & $4.80 \times 10^{3}$ & $3.04 \times 10^{-17}$ \\
\hline & 1250 & $7.20 \times 10^{3}$ & $9.71 \times 10^{-18}$ \\
\hline & 1208 & $1.47 \times 10^{4}$ & $2.69 \times 10^{-18}$ \\
\hline & 1147 & $7.20 \times 10^{4}$ & $2.44 \times 10^{-19}$ \\
\hline & 1059 & $9.36 \times 10^{4}$ & $2.61 \times 10^{-20}$ \\
\hline \multirow{10}{*}{ Co } & 1538 & $2.40 \times 10^{3}$ & $1.60 \times 10^{-14}$ \\
\hline & 1425 & $2.40 \times 10^{3}$ & $2.08 \times 10^{-15}$ \\
\hline & 1353 & $3.00 \times 10^{3}$ & $6.23 \times 10^{-16}$ \\
\hline & 1305 & $4.80 \times 10^{3}$ & $2.65 \times 10^{-16}$ \\
\hline & 1235 & $7.20 \times 10^{3}$ & $3.44 \times 10^{-17}$ \\
\hline & 1191 & $2.34 \times 10^{4}$ & $1.36 \times 10^{-17}$ \\
\hline & 1146 & $1.26 \times 10^{4}$ & $3.79 \times 10^{-18}$ \\
\hline & 1103 & $2.58 \times 10^{4}$ & $1.05 \times 10^{-18}$ \\
\hline & 1061 & $9.18 \times 10^{4}$ & $1.62 \times 10^{-19}$ \\
\hline & 1000 & $1.51 \times 10^{5}$ & $3.12 \times 10^{-20}$ \\
\hline
\end{tabular}

Figure 6 shows the plot of logarithm of the preexponential. factor versus the activation energy for the diffusion in the $\gamma$-phase TiAl. A linear relationship between $\ln \mathrm{D}_{0}$ and $Q$ in Fig. 6 suggests that the diffusion mechanism for iron and cobalt solutes in the $\gamma$-phase TiAl is the same as that for the self-diffusion of titanium /10/, i.e., a vacancy mechanism. Recent studies on the formation of thermal vacancy in the $\gamma$-phase TiAl by means of positron lifetime spectroscopy $/ 12 /$ and by calculations within a nearest-neighbor-bond model /13/ suggest that thermal vacancies predominantly exist on the $\mathrm{Ti}$ sublattice together with a high concentration of antisite atoms on both sublattices. According to Hashimoto et al. $/ 14 /$, iron solute occupies both sides in the sublattices of the Al-rich TiAl compound, while cobalt solute occupies Al-site preferentially in the compound. However, as shown in Fig. 5, the diffusivity of cobalt is nearly equal to the self-diffusivity of titanium. 


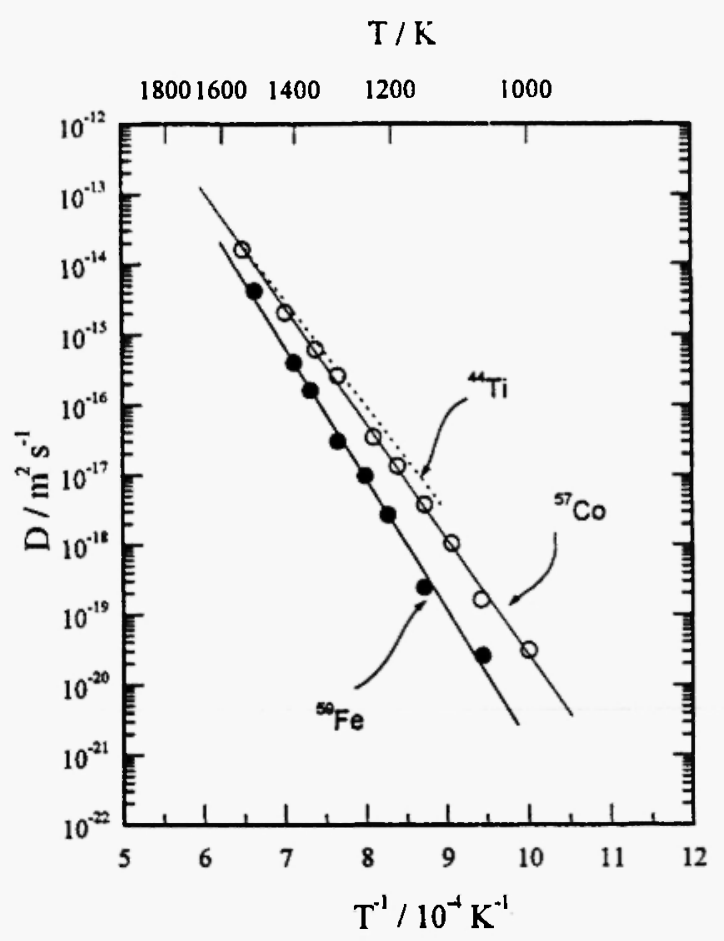

Fig. 5: Arrhenius plots of diffusion coefficients of ${ }^{59} \mathrm{Fe}$ and ${ }^{57} \mathrm{Co}$ in comparison with self-diffusion of ${ }^{44} \mathrm{Ti}$ in Ti-54at\%Al alloy.

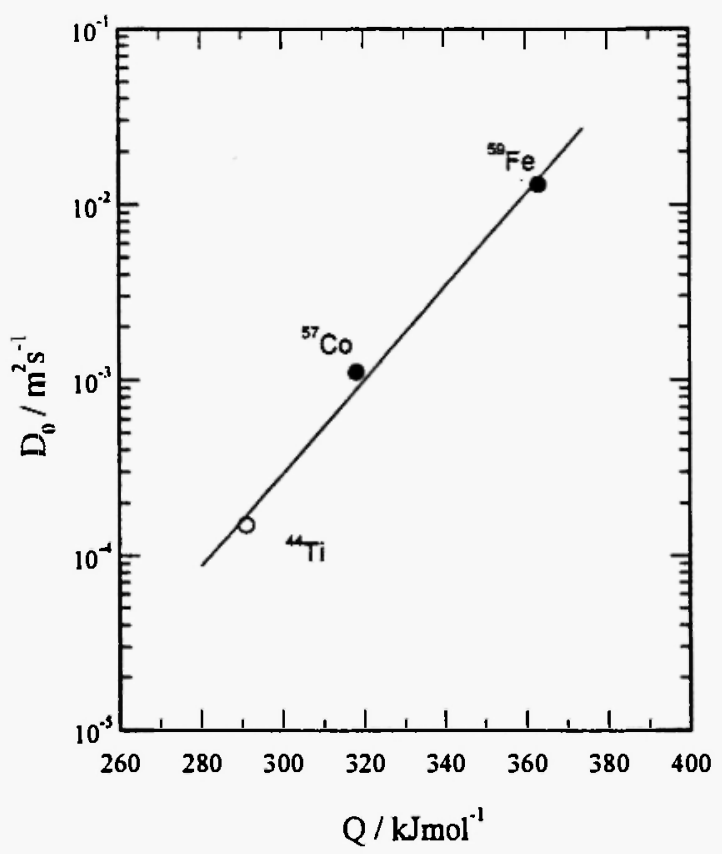

Fig. 6: Plot of logarithm of $D_{0}$ vs $Q$ for diffusion of ${ }^{59} \mathrm{Fe},{ }^{57} \mathrm{Co}$ and ${ }^{44} \mathrm{Ti}$ in $\mathrm{Ti}-54 \mathrm{at} \% \mathrm{Al}$ alloy.
Therefore, cobalt atom occupies the Ti sublattice as the antisite atom and/or occupies both sublattices.

\section{CONCLUSION}

Tracer diffusion coefficients of ${ }^{59} \mathrm{Fe}$ and ${ }^{57} \mathrm{Co}$ in an intermetallic compound TiAl containing 54at\% $\mathrm{Al}$ have been determined in the temperature range between 1000 and $1538 \mathrm{~K}$. The temperature dependence of the diffusion coefficients are expressed by the linear Arrhenius relationships with the pre-exponential factor $1.30 \times 10^{-2} \mathrm{~m}^{2} \mathrm{~s}^{-1}$ and the activation energy $363 \mathrm{kJmol}^{-1}$ for iron diffusion and with $1.12 \times 10^{-3} \mathrm{~m}^{2} \mathrm{~s}^{-1}$ and 318 $\mathrm{kJmol}^{-1}$ for cobalt diffusion. These diffusion parameters suggest that in the $\gamma$-phase TiAl both iron and cobalt atoms diffuse by a vacancy mechanism.

\section{ACKNOWLEDGMENT}

The authors are indebted to Mr. T. Sugawara (Institute for Materials Research, Tohoku University) for zone-melting of the $\gamma$-phase TiAl compound.

\section{REFERENCES}

1. G. Sauthoff, Z. Metallk., 80, 337 (1989).

2. G. Sauthoff, Z. Metallk., 81, 885 (1990).

3. M. Yamaguchi, Mater. Sci. Tech., 8, 299 (1992).

4. Y. Murata, M. Morinaga and Y. Takeda, Mater. Trans. JIM, 33, 419 (1992).

5. H. Wever, J. Hunecke and G. Frohberg, $Z$. Metallk., 80, 389 (1989).

6. H. Bakker, in:Diffusion in Solid Metals and Alloys, H. Mehrer (Ed), Landolt-Bömstein, New Series, Group 3, Vol. 26, Springer, Berlin, 1990; p. 213.

7. H. Mehrer, Mater. Trans. JM, 37, 1259 (1996).

8. K. Ouchi, Y. Iijima and $\mathrm{K}$. Hirano, in: Titanium '80 Science and Technology, H. Kimura and $\mathrm{O}$. Izumi (Eds.), AIME, New York, 1980; p. 559.

9. W. Sprengel, N. Oikawa and H. Nakajima, Intermetallics, 4, 185 (1996).

10. S. Kroll, H. Mehrer, N. Stolwijk, C. Herzig, R. Rosenkranz and G. Frommeyer, Z. Metallk, 83, 591 (1992). 
11. P. Shewmon, Diffusion In Solids, 2nd Edition, The Minerals, Metals and Materials Society, Warrendale, 1989; p. 86.

12. U. Brossmann, R. Wüschum, K. Badura and H.-E. Schaefer, Phys. Rev., 49, 6457 (1994).

13. K.A. Badura and H.-E. Schaefer, Z. Metallk, 84, 405 (1993).

14. K. Hashimoto, H. Doi, T. Tsujimoto and T. Suzuki, Mater. Trans. JIM, 32, 574 (1991). 
